\title{
Outpatient care in acute and prehospital emergency medicine by emergency medical and patient transport service over a 10-year period: a retrospective study based on dispatch data from a German emergency medical control center (OFF-RESCUE)
}

\author{
Marc S. Schehadat ( $\square$ marc.schehadat@hotmail.de ) \\ Goethe-Universitat Frankfurt am Main Fachbereich 16 Medizin https://orcid.org/0000-0003-4217-6066 \\ Guido Scherer \\ District Administration Mainz-Bingen
}

\section{David A. Groneberg}

Goethe-Universität Frankfurt am Main Fachbereich 16 Medizin: Goethe-Universitat Frankfurt am Main Fachbereich 16 Medizin

\section{Manfred Kaps \\ University Hospital Giessen}

\section{Michael H.K. Bendels}

Goethe-Universitat Frankfurt am Main Fachbereich 16 Medizin

\section{Research article}

Keywords: OFF-Mission, ON-Mission, Emergency Medical Control Center, triaged, dispatched, rural, urban, job cycle time, prehospital emergency care, Emergency medical dispatch

Posted Date: November 12th, 2020

DOI: https://doi.org/10.21203/rs.3.rs-103683/v1

License: (c) (i) This work is licensed under a Creative Commons Attribution 4.0 International License. Read Full License

Version of Record: A version of this preprint was published on March 9th, 2021. See the published version at https://doi.org/10.1186/s12873-021-00424-4. 


\section{Abstract}

\section{Background}

The number of operations by the German emergency medical service almost doubled between 1994 and 2016. The associated expenses increased by $380 \%$ in a similar period. Operations with treatment on-site, which retrospectively proved to be misallocated (OFF-Missions), have a substantial proportion of the assignment of the emergency medical service (EMS). Besides OFF-Missions, operations with patient transport play a dominant role (named as ON-Missions). The aim of this study is to work out the medical and economic relevance of both operation types.

\section{Methods}

This analysis examined $\mathrm{N}=819,780$ missions of the EMS and patient transport service (PTS) in the catchment area of the emergency medical control center (EMCC) Bad Kreuznach over the period from 01/01/2007 to 12/31/2016 in terms of triage and disposition, urban-rural distribution, duration of operations and economic relevance $(\mathrm{p}<.01)$.

\section{Results}

$53.4 \%$ of ON-Missions are triaged with the indication non-life-threatening patient transport; however, $63.7 \%$ are processed by the devices of the EMS. Within the OFF-Mission cohort, $78.2 \%$ and $85.8 \%$ are triaged or dispatched for the EMS. $74 \%$ of all ON-Missions are located in urban areas, $26 \%$ in rural areas; $81.3 \%$ of rural operations are performed by the EMS. $66 \%$ of OFF-Missions are in cities. $93.2 \%$ of the remaining $34 \%$ of operations in rural locations are also performed by the EMS. The odds for both ON- and OFF-Missions in rural areas are significantly higher than for PTS $\left(\mathrm{OR}_{\mathrm{ON}}\right.$ 3.6, 95 \% Cl 3.21-3.30; $\mathrm{OR}_{\mathrm{OFF}} 3.18,95$ \% Cl 3.04-3.32). OFF-Missions last 47.2 minutes (SD 42.3; $\left.\mathrm{Cl} 46.9-47.4\right)$, while ON-Missions are processed after 79.7 minutes on average (SD 47.6; Cl 79.6-79.9). ON-Missions generated a turnover of more than $€ 114$ million, while OFF-Missions made a loss of almost $€ 13$ million.

\section{Conclusions}

This study particularly highlights the increasing utilization of emergency devices; especially in OFF-Missions, the resources of the EMS have a higher number of operations than PTS. OFF-Missions cause immensely high costs due to misallocations from an economic point of view. Appropriate patient management appears necessary from both medical and economic perspective, which requires multiple solution approaches.

\section{Background}

The utilization of the resources of the emergency medical service (EMS) and patient transport service (PTS) in the public healthcare system has become increasingly important in recent years [1,2,3]; while in Germany in 1994 about 9.5 million operations were performed, in 2016 there were already 16.4 million missions [4]. In retrospect, most missions (70\%) were non-urgent and mainly took place in cities $[5,6,7,8]$. In particular, the number of outpatient medical contacts in emergency medicine accounted for a significant proportion; this was rated as $16-41.7 \%[9,10,11,12,13]$. Here, patients often misjudged the urgency of their complaints [14]. This mainly concerned vulnerable patient groups such as elders, children, young adults and homeless people; neurological and traumatological indications were frequent reasons for emergency calls; in this context, the information in the relevant literature for neurological (1-29\%) and traumatological complaints such as injuries caused by falls $(9-56 \%)$ vary $[15,16,17,18]$.

A distinction is made between assistance services, where a medical service is performed on-site, and operations, where no patient is present at the emergency location [19]. Statistically, spurious trips are recorded as a quota by the German Federal Health Monitoring; in 2013, a proportion of $7.4 \%$ of all operations of the public EMS was documented [19]. In 
contrast to patient transportations, assistance services and spurious trips are not remunerated in Rhineland-Palatinate; these costs must be cross-financed by the organizations that run the EMS; they are included in the operating expenses [20]. Assistant services are not officially recorded by statistics. In order to reduce these non-life-threatening operations in favour of efficient patient management, various solution approaches have been applied in the past; processes of the emergency medical control center (EMCC) were improved in respect of emergency call handling, which, however, led to an over-prioritization (false positive assignment of a higher priority level) of many patients [21,22,23]. In addition, protocols for handling low-priority patients have been successfully implemented, which lead either to the outpatient usage of a nurse or to telephone consultation $[24,25]$. The decision on whether a patient should be conveyed, should not be made by paramedics due to a lack of patient safety; several studies have shown inconsistent findings $[26,27,28]$. Participation of general practitioners in prehospital emergency care would help [29]. During non-indicated operations, emergency devices are not available for life-threatening patients, which delays the ambulance response time. As a result, the outcome of patients with time-critical emergency get worse [30,31,32].

A similar development of overuse is also apparent in the emergency departments [33]. Important reasons are on the one hand the lack of awareness of medical necessity and on the other hand the fact that young people in particular see the emergency department as a contact point outside the opening hours of general practitioners as a substitute service $[34,35,36]$. For most patients (66\%), outpatient medical care is sufficient, but it still caused an immense effort [37]. From an economic point of view, healthcare costs in Germany increased by $236 \%$ from about $€ 159$ to $€ 375$ billion between 1992 and 2017. The EMS even registered a rise of $380 \%$, the share of healthcare costs rose from $0.8 \%$ to $1.3 \%$ [38].

In the following, the term OFF-Mission will describe all operations that did not prehospitally result in a patient transportation, while ON-Missions describe completed transports. The aim of this retrospective, explorative study is to compare $\mathrm{ON}$ - and OFF-Missions in terms of urban-rural distribution, job cycle time and economic relevance.

\section{Current procedure for the prioritization of outpatient emergency missions}

In Germany, all medical emergencies should be reported via the European emergency number 112 to the responsible EMCC, which organizes the non-police emergency response. In the rescue service area Bad Kreuznach/RhinelandPalatinate, patient transports can be requested via the same institution, but also under the service number 19222 . The emergency call processing at the EMCC is performed in several steps; at first, the call handler prioritizes the urgency of the request based on his initial assessment, which is followed by the decision on the appropriate device (Triaged). A distinction is made between emergency devices such as emergency rescue vehicles, which are primarily responsible for emergency events, and patient transport vehicle, which carry out adaptable transports, e.g. to planned medical examinations. In the next step, the so-called dispatcher may be forced to dispatch an inadequate device due to organizational limitations regarding the lack of availability of correct resources and by consideration of the entire overall scenario (Dispatched). In general, the most important principle is the fastest possible dispatch of a device to a lifethreatening patient; in daily practice, this means that an immediate available patient transport vehicle with medical resources may can provide assistance more quickly than an emergency rescue vehicle with extensive diagnostic and therapeutic facilities that is still tied up in an operation, because its time availability cannot be estimated at the time the emergency call is received.

\section{Methods}

\section{Data acquisition}

One of the eight EMCCs in Rhineland-Palatinate/Germany, located in Bad Kreuznach, was selected for the data collection. This EMCC is responsible for the three districts Bad Kreuznach, Birkenfeld and Rhine-Hunsrück with 341,215 inhabitants, which represent $8.4 \%$ of the total population of the federal state and an area of $2631.88 \mathrm{~km}^{2}$ with a 
proportion of $13.3 \%$ of the territory of Rhineland-Palatinate [39]. To classify between city and rural municipality, only the status given by the government was considered.

For this research the following variables were used from the SQL database:

radio coding of the devices, emergency scene by location, emergency scene by object from any existing database entry, type of operation, operation keyword, diagnosis, comments, type of transport, first operation code (corresponds to indication), short comment of first operation code, second operation code, short comment of second operation code, third operation code, short comment of third operation code, caller, destination, destination district, operation opening time, takeover time, end time of operation, time of alerting, job cycle time.

\section{Study type}

This study is a descriptive analysis. In the observation period from 01/01/2007 to $12 / 31 / 2016, \mathrm{~N}=819,780$ ON- and OFFMissions of the public emergency medical and patient transport service in the catchment area of the EMCC Bad Kreuznach were included. All operations that could not be clearly assigned to a type of transport or prehospital device, were test operations, duplicates or placeholders and were performed either by civil protection or first responder were excluded.

\section{Dispatching types}

During the investigation period, two different types of dispatching could be distinguished due to a change in the control center software: from 2007 to 2011, the selection of the correct device based on emergency and operation categories such as internal emergency. From 2012 to 2016, the disposition procedure was performed according to the so-called operation codes (EC), which code both symptoms/ suspected diagnoses and organizational indications, such as acute stroke or technical rescue. This resulted, among other things, in the transport types $R$ for an urgent operation in an emergency rescue vehicle or $K L$ for a non-urgent transport in horizontal position in a patient transport vehicle. For this reason, the query script had to contain the old and current operation indications.

\section{Remuneration}

The fees for operations of the EMS corresponded to the level of 2016 and were used as a basis for the 10-year period investigated. Extra charges for nights, Sundays and public holidays as well as mileage and emergency physician's flat rate and control center fees were not taken into account. Here, a simplified attempt will be made to determine the value of $\mathrm{ON}$ - and OFF-Missions or their lost revenues. The operating minute of the specific device was used as the basis for calculation.

\section{Data integration}

The data sets collected were processed by using Microsoft Excel (Version 16.33, Redmond, WA/USA); subsequently they were anonymized, corrected and standardized.

\section{Statistical analysis}

The independent samples t test was performed for figure 2 with the variables EM-Typ (corresponds to Dispatched) and Einsatzart (corresponds to Triaged), for figure 3 with Ortsteil (corresponds to type of mission) and EM-Typ and for figure 4 with Gesamtdauer (corresponds to job cycle time). The statistical significance level was set at $p<.01$. The relevant topics were analyzed statistically by using SPSS (Version 25, IBM Corp., Armonk, NY/USA).

\section{Results}




\section{Triage of emergency calls and dispatching of resources}

Among the ON-Missions, 53.4\% ( $N=370,394)$ of all telephone requests were for PTS, while the remaining $46.6 \%$ $(\mathrm{N}=322,717)$ were classified as emergencies (Fig. 2a). Looking at the dispatched emergency devices, the resources of the EMS provided $63.7 \%(\mathrm{~N}=441,300)$ of all operations, while PTS only provided $36.3 \%(\mathrm{~N}=251,811)$. The triaged $(78.2 \%$; $\mathrm{N}=99,033)$ and dispatched OFF-Missions $(85.8 \%, \mathrm{~N}=108,647)$ were predominantly assigned to the vehicles of the EMS (Fig. 2b). The proportion of the PTS is relatively small, both for triaged $(21.8 \% ; \mathrm{N}=27,636)$ and dispatched operations $(14.2 \% ; \mathrm{N}=18,022)$.

\section{Urban-rural distribution of ON- and OFF-Missions}

From 2007 to 2016, 693,111 ON- and 126,669 OFF-Missions were recorded. 68.5\% of all operations took place in the city, $25.6 \%$ in rural areas and $6 \%$ in foreign or neighboring catchment areas. $74 \%$ of all ON-Missions were in urban emergency locations $(\mathrm{N}=483,884) ; 57.1 \%$ were performed by EMS and $42.9 \%$ by PTS. The remaining $26 \%$ of all ON-Missions took place in a rural context $(\mathrm{N}=169,727)$; EMS accounted for $81.3 \%$ and PTS for $18.8 \%$ of the operations. $66.1 \%$ of all OFFMissions were in urban emergency locations ( $\mathrm{N}=77,519)$; whereby $81.2 \%$ were performed by emergency devices and $18.7 \%$ patient transport vehicles. The remaining $34 \%$ of all OFF-Missions took place in a rural context $(\mathrm{N}=39,905) ; 93.2 \%$ were carried out by EMS and $6.8 \%$ by PTS. The analysis of the urban and rural distribution of operations did not include the missions of the devices of the EMCC Bad Kreuznach to emergency locations in neighboring catchment areas

$\left(\mathrm{N}_{\text {foreign }}=48,745, \mathrm{~N}_{\text {OFF_foreign }}=7.3 \%, \mathrm{~N}_{\mathrm{ON} \_ \text {foreign }}=5.7 \%\right)$.

The odds of an ON-Mission in a rural location performed by an emergency vehicle were more than three times higher than by a patient transport vehicle (Fig. 3) (OR 3.26, 95\% Cl 3.21-3.30). This was similar for OFF-Missions (OR 3.18, 95\% $\mathrm{Cl} 3.04-3.32)$. In the urban setting it was vice versa; the probability of a patient transportation (OR $0.31,95 \% \mathrm{Cl} 0.30-0.31)$ and an OFF-Mission by an emergency vehicle was smaller than by a patient transport vehicle (OR $0.31,95 \% \mathrm{Cl} 0.30$ 0.33).

\section{Job cycle time of ON- and OFF-Missions}

The total mean of the job cycle time of both mission classifications was 74.7 minutes ( $\mathrm{SD}=42.3, \mathrm{Cl}$ 46.9-47.4) (Fig. 4). The OFF-Missions had a smaller mean of 47.2 minutes (SD 42.3; Cl 46.9-47.4) compared to the ON-Missions, which lasted 79.7 minutes (SD 47.6; Cl 79.6-79.9). In both operation cohorts, the shortest missions were reported to last about 2 seconds and the longest about 24 hours.

\section{Economic view}

Assuming that the operation minute of an emergency rescue vehicle was worth $€ 3.50$ at an average job cycle time of 79 minutes, the costs for emergency transports amounted to more than $€ 100$ million for the period under investigation (Table 1). Based on this calculation and an average job cycle time of an OFF-Mission of approximately 44 minutes, the lost revenue per mission was $€ 155.40$ (Table 2). With a total of 67,831 OFF-missions, this resulted in a deficit of more than $€ 10$ million. Across all mission categories, this resulted in a total deficit of $€ 12,724,513$, which corresponded to $11.1 \%$ of the turnover of all ON-Missions at $€ 114,506,436$.

\section{Discussion}

\section{Triage and dispatching}

The results of the ON-Missions show a clear disproportion in the triaging and disposition of PTS-induced operations (Fig. 2). $63.7 \%$ of all operations were performed by the EMS, although only $46.6 \%$ had an emergency indication and thus a 
reason for the dispatching of an emergency device. Accordingly, $17.1 \%$ of all ON-Missions by an emergency device were operations with a PTS-indication. In contrast to the PTS, the existence of the 24-hour availability of emergency devices played an important role; operations triaged with PTS-indications were performed by emergency rescue vehicles during night hours or on holidays and weekends. A provision of patient transport vehicles could remedy this situation. It was also likely that the frequent incidence of non-urgent patient transportations in main operating periods played a decisive role in the misappropriation of emergency devices. OFF-Missions however were predominantly triaged as urgent operations, which could be explained by EMS-indications and/or lack of prior medical contact. Over-prioritization seemed to be essential at this point. For some emergency diseases, the need for transport did not arise (e.g. unsuccessful resuscitation, death confirmation). Here the disposition rate was also slightly higher to the detriment of emergency devices (+7.6\%). Patient transport service played a subordinate role, which showed the scheduling of such operations (so-called appointment trips), where the majority of patients have already had contact with a doctor.

\section{Urban-rural distribution}

Almost 3/4 (74.1\%) of all ON-Missions were in urban areas, which only accounted for $44.9 \%$ of the total population (Fig. 3) [40]. The demand for patient transport services in rural areas was very low for ON- and OFF-Missions (4.9\% vs. $2.3 \%$ ). Relatively more OFF- than ON-Missions took place in rural areas (34\% vs. $26 \%$ ), which were almost entirely provided by emergency devices in the case of emergency events (31.7\% vs. $21.1 \%)$. The use of prehospital services was therefore not significantly determined by the number of inhabitants, but rather other factors played a dominant role. Specific infrastructural institutions such as nursing homes, where elderly and multimorbid people usually lived, were found almost exclusively in cities and call for emergency services more frequently $[41,42,43,44,45]$. The anonymity of the city, with the missing support of the family and neighborhood, and the population's increased expectations also caused the number of operations to rise rapidly $[46,47]$. In urban areas are also more vulnerable population groups (e.g. homeless people), who often presented themselves as frequent users of emergency services [42,45,48,49,50,51].

\section{Job cycle time}

On average, the job cycle time of ON- and OFF-Missions differs by 32.5 minutes, which could be explained by the lack of patient transfer and handover time in OFF-Missions (Fig. 4). Very short job cycle times of 2 seconds resulted from incorrect dispositions of the EMCC, which have already been received by the dispatched vehicle crew via radio. Longlasting operations of several hours to almost 24 hours are explained by missed sign offs of the emergency device via radio or due to long-distance trips.

\section{Remuneration}

In both, the ON and OFF cohorts, emergency devices (mainly emergency rescue vehicle and emergency practitioners' operational vehicle) generated the most ( $€$ 108,822,272) and recorded the largest number of lost revenues ( $€$ $12,495,564)$. In general, OFF-Missions were not reimbursed by the funding agencies and that's why this was referred to as lost revenues. At this point, the different basic rate of the prehospital devices has not been ignored. The number of missions by emergency practitioners' cars was very small, as they have been increasingly replaced by emergency practitioners' operational vehicle and were now used almost exclusively as intensive care transport vehicles for emergency physician-assisted transfers at exclusive locations. Long access distances lead to the large mean. Interestingly, the means of all prehospital devices appeared very homogeneous, with the exception of the abovementioned vehicle type. The reason for this could be the longer residence time of emergency devices at the scene for the treatment of the patient with shorter transfer times and the shorter residence time of patient transport vehicles with longer transport routes for special examinations.

\section{Conclusions}


This study highlights in particular the increasing use of emergency devices, which is also associated with a progressive misappropriation of these vehicles; especially in the case of OFF-Missions, the EMS records a higher number of operations than PTS; the reasons are a combination of the fact, that emergency operations and their course are not plannable or predictable. From an economic point of view, OFF-Missions are a non-profit business for the service providers; immensely high revenues are missing, but in the present work these are only calculated in a simplified way and thus presented to a lesser extent than it is actually the case. Therefore, better patient management appears to make sense from both sides - the medical and the economic point of view. Practical experience has shown that simple assistance is more time-consuming than normal emergency events, on the one hand because of legal uncertainty in the case of trivial indications and on the other hand because of complex medical care (e.g. unsuccessful resuscitation). In order to be able to make statements about the increased effort of simple assistance, the effective treatment time (= onsite time) between ON- and OFF-Missions should be compared in future studies.

\section{Abbreviations}

EC: Einsatzcode (in German; corresponds to the operation code)

EM: Einsatzmittel (in German; corresponds to prehospital devices)

EMCC: Emergency Medical Control Center

EMS: Emergency Medical Service

KL: Krankentransport liegend (in German; corresponds to non-urgent transport in horizontal position)

PTS: Patient Transport Service

R: Rettungswagen (in German; corresponds to the emergency rescue vehicle)

SQL: Structured Query Language

\section{Declarations}

\section{Availability of data and materials}

The data that support the findings of this study are available from the Department of Civil Protection of the district administration Mainz-Bingen/Germany, but restrictions apply to the availability of these data, which were used under license for the current study and are therefore not publicly available. The Data were made available upon the authors reasonable request and with permission of the Department of Civil Protection of the district administration MainzBingen/Germany.

\section{Acknowledgements}

We thank the team of the EMCC Bad Kreuznach for providing the data.

\section{Funding}

None

\section{Consent of publication}

None. 


\section{Competing interests}

The authors declare that they have no competing interests.

\section{Author's contributions}

\section{Contributions}

MS was the lead investigator and contributed to all aspects of the study. MHKB contributed to all aspects of the study. GS provided the data.

All authors participated in critical revision and approved the final manuscript.

Corresponding author

Correspondence to Marc Schehadat.

\section{Author's information}

None.

\section{Ethics approval and consent to participate}

Not applicable.

\section{References}

[1] Lowthian JA, Cameron PA, Stoelwinder JU, Curtis A, Currell A, Cooke MW, et. Al. Increasing utilization of emergency ambulances. Aust Health Rev Publ Aust Hosp Assoc. 2011;35:63-9

[2] Pittet V, Burnand B, Yersin B, Carron PN. Trends of pre-hospital emergency medical services activity over 10 years: a population-based registry analysis. BMC Health Serv Res. 2014;14:380

[3] Møller TP, Ersbøll AK, Tolstrup JS, Østergaard D, Viereck S, Overton J et. Al. Why and when citizens call for emergency help: an observational study of 211,193 medical emergency calls. Scand J Trauma Resusc Emerg Med. 2015;23:88

[4] Bundesanstalt für Straßenwesen, Leistungen des Rettungsdienstes, abgerufen am 29.04.2020, von http://www.gbebund.de/oowa921-install/servlet/oowa/aw92/dboowasys921.xwdevkit/xwd_init?

be.isgbetol/xs_start_neu/\&p_aid=i\&p_aid=68217013\&nummer=459\&p_sprache=D\&p_indsp=99999999\&p_aid=62092358 gg

[5] Zakariassen E, Burman RA, Hunskaar S. The epidemiology of medical emergency contacts outside hospitals in Norway - a prospective population-based study. Scand J Trauma Resusc Emerg Med 18, 9 (2010) doi:10.1186/17577241-18-9

[6] Burns B, Hansen ML, Valenzuela S, Summers C, Van Otterloo J, Skarica B, Warden C, Guise JM (2016) Unnecessary Use of Red Lights and Sirens in Pediatric Transport, Prehospital Emergency Care, 20:3, 354361, DOI: 10.3109/10903127.2015.1111477

[7] Magnusson C, Axelsson C, Nilsson L et al. The final assessment and its association with field assessment in patients who were transported by the emergency medical service. Scand J Trauma Resusc Emerg Med 26, 111 (2018). https://doi.org/10.1186/s13049-018-0579-x 
[8] Hegenberg K, Trentzsch H, Gross S et al. Use of pre-hospital emergency medical services in urban and rural municipalities over a 10-year period: an observational study based on routinely collected dispatch data. Scand J Trauma Resusc Emerg Med 27, 35 (2019). https://doi.org/10.1186/s13049-019-0607-5

[9] Hoikka M, Silfvast T, Ala-Kokko TI. A high proportion of prehospital emergency patients are not transported by ambulance: a retrospective cohort study in Northern Finland. Acta Anaesthesiologica Scandinavica 2017

[10] Snooks H, Williams S, Crouch R, Foster T, Hartley-Sharpe C, Dale J. NHS emergency response to 999 calls: alternatives for cases that are neither life threatening nor serious. BMJ. 2002 Aug 10;325(7359):330-3. Doi: 10.1136/bmj.325.7359.330. PMID: 12169513; PMCID: PMC1123835.

[11] Phillips SE, Gaskin PS, Byer D, Cadogan WL, Brathwaite A, Nielsen AL. The Barbados Emergency Ambulance Service: High Frequency of Nontransported Calls. Emerg Med Int. 2012;2012:659392. Doi: 10.1155/2012/659392. Epub 2012 Nov 7.

[12] Alrazeeni DM, Sheikh SA, Mobrad A, Al Ghamdi M, Abdulqader N, Al Gadgab M, Al Qahtani M, Al Khaldi B. Epidemiology of non-transported emergency medical services calls in Saudi Arabia. Saudi Med J. 2016 May;37(5):575-8. Doi: 10.15537/smj.2016.5.13872. PMID: 27146623; PMCID: PMC4880660.

[13] Norberg G, Sundström BW, Christensson L, Nyström M, Herlitz J (2015) Swedish emergency medical services' identification of potential candidates for primary healthcare: Retrospective patient record study, Scandinavian Journal of Primary Health Care, 33:4,311-317, DOI: 10.3109/02813432.2015.1114347

[14] Andrews H, Kass L. Intern Emerg Med (2018) 13: 893. https://doi.org/10.1007/s11739-018-1792-3

[15] Ebben RH, Vloet LC, Speijers RF et al. A patient-safety and professional perspective on non-conveyance in ambulance care: a systematic review. Scand J Trauma Resusc Emerg Med25, 71 (2017) doi:10.1186/s13049-017-0409-6

[16] Vloet LCM, de Kreek A, van der Linden EMC. et al. A retrospective comparison between non-conveyed and conveyed patients in ambulance care. Scand J Trauma Resusc Emerg Med 26, 91 (2018) doi:10.1186/s13049-018-0557-3

[17] Durant E, Fahimi J (2012) Factors Associated with Ambulance Use Among Patients with Low-Acuity Conditions, Prehospital Emergency Care, 16:3, 329-337, DOI: 10.3109/10903127.2012.670688

[18] Marks PJ, Daniel TD, Afolabi O, et al Emergency (999) calls to the ambulance service that do not result in the patient being transported to hospital: an epidemiological study Emergency Medicine Journal 2002;19:449-452.

[19] Schmiedel R, Behrendt H, FORPLAN DR. SCHMIEDEL GmbH Forschungs- und Planungsgesellschaft für das Rettungswesen, Bundesanstalt für Straßenwesen, Leistungen des Rettungsdienstes 2012/13, Analyse des Leistungsniveaus im Rettungsdienst für die Jahre 2012 und 2013, Bergisch Gladbach, Fachverlag NW in der Carl Schünemann Verlag GmbH, 2015, 4.1.8, S. 21

[20] Sec. 12 para. 1, sentence 3 RettDG (Landesgesetz über den Rettungsdienst sowie den Notfall- und Krankentransport) vom 22. April 1991

[21] Snooks H, Kearsley N, Dale J, Halter M, Redhead J, Cheung WY. Towards primary care for non-serious 999 callers: results of a controlled study of "Treat and Refer" protocols for ambulance crews. Qual Saf Health Care. 2004 Dec;13(6):435-43. doi: 10.1136/qhc.13.6.435. PMID: 15576705; PMCID: PMC1743925.

[22] Ek B, Edström P, Toutin A, Svedlund M. Reliability of a Swedish pre-hospital dispatch system in prioritizing patients. Int Emerg Nurs. 2013 Apr;21(2):143-9. doi: 10.1016/j.ienj.2011.11.006. Epub 2011 Dec 29.

Page 9/15 
[23] Torlén K, Kurland L, Castrén M et al. A comparison of two emergency medical dispatch protocols with respect to accuracy. Scand J Trauma Resusc Emerg Med 25, 122 (2017). https://doi.org/10.1186/s13049-017-0464-z

[24] Magnusson C, Källenius C, Knutsson S, Herlitz J, Axelsson C, Pre-hospital assessment by a single responder: The Swedish ambulance nurse in a new role: A pilot study. Int Emerg Nurs. 2016 May;26:32-7. doi:

10.1016/j.ienj.2015.09.001. Epub 2015 Oct 21.

[25] Dale J, Williams S, Foster T, et al Safety of telephone consultation for "non-serious" emergency ambulance service patients. BMJ Quality \& Safety 2004;13:363-373.

[26] Peyravi M, Örtenwall P, Khorram-Manesh A. Can Medical Decision-making at the Scene by EMS Staff Reduce the Number of Unnecessary Ambulance Transportations, but Still Be Safe?. PLOS Currents Disasters. 2015 Jun 30. Edition 1. doi: 10.1371/currents.dis.f426e7108516af698c8debf18810aa0a.

[27] Hauswald M (2002) Can Paramedics Safely Decide Which Patients Do Not Need Ambulance Or Emergency Department Care? Prehosp Emerg Care. 6:4, 383-386, DOI: 10.1080/10903120290937978

[28] Coster J, O'Cathain A, Jacques R, Crum A, Siriwardena AN, Turner J (2019) Outcomes for Patients Who Contact the Emergency Ambulance Service and Are Not Transported to the Emergency Department: A Data Linkage Study, Prehosp Emerg Care. 23:4, 566-577, DOI: 10.1080/10903127.2018.1549628

[29] Hjortdahl M, Zakariassen E, Wisborg T. The role of general practitioners in the prehospital setting, as experienced by emergency medicine technicians: a qualitative study. Scand J Trauma Resusc Emerg Med 22, 47 (2014). https://doi.org/10.1186/s13049-014-0047-1

[30] Chowdhury S, Navsaria PH, Edu S, Nicol AJ. (2016). The effect of emergency medical services response on outcome of trauma laparotomy at a Level 1 Trauma Centre in South Africa. South African Journal of Surgery, 54(4), 17-21. Retrieved February 02, 2020, from http://www.scielo.org.za/scielo.php?script=sci_arttext\&pid=S0038$23612016000400006 \&$ Ing=en\&tlng=en.

[31] Vukmir RB. Survival from prehospital cardiac arrest is critically dependent upon response time. Resuscitation. 2006 May;69(2):229-34. Epub 2006 Feb 23. https://doi.org/10.1016/j.resuscitation.2005.08.014

[32] Shy BD, Rea TD, Becker LJ, Eisenberg MS. Time to intubation and survival in prehospital cardiac arrest. Prehosp Emerg Care. 2004 Oct-Dec;8(4):394-9. https://doi.org/10.1016/j.prehos.2004.06.013

[33] Di Somma S, Paladino L, Vaughan L et al. Overcrowding in emergency department: an international issue. Intern Emerg Med 10, 171-175 (2015). https://doi.org/10.1007/s11739-014-1154-8

[34] Burns, TR. Contributing factors of frequent use of the emergency department: A synthesis. Int Emerg Nurs. 2017 Nov;35:51-55. doi: 10.1016/j.ienj.2017.06.001. Epub 2017 Jul 1. https://doi.org/10.1016/j.ienj.2017.06.001

[35] O'Keeffe C, Mason S, Jacques R, Nicholl J (2018) Characterising non-urgent users of the emergency department (ED): A retrospective analysis of routine ED data. PLoS ONE 13(2): e0192855.

https://doi.org/10.1371/journal.pone.0192855

[36] Schmiedhofer M, Searle J, Slagman A, Frick J, Ruhla S, Möckel M. Perception of the Emergency Department for Outpatient Care in a Rural Region in Saxony-Anhalt: A Qualitative Survey of Patients and General Practitioners. Dtsch Med Wochenschr. 2017 May;142(10):e61-e73. doi: 10.1055/s-0043-100639. Epub 2017 Mar 29. 
[37] Trentzsch H, Dodt C, Gehring C, Veser A, Jauch KW, Prückner S; Studiengruppe „Runder Tisch Notfallversorgung Landeshauptstadt München“. Analysis of Treatment Figures in the Munich Emergency Rooms 2013-2014.

Gesundheitswesen. 2019 Aug 8. doi: 10.1055/a-0925-8989. [Epub ahead of print]

[38] Gesundheitsberichterstattung des Bundes, Gesundheitsausgabenrechnung, Statistisches Bundesamt, Zweigstelle Bonn (2019). Abgerufen am 29.02.2020, von http://www.gbe-bund.de/oowa921-

install/servlet/oowa/aw92/dboowasys921.xwdevkit/xwd_init?

gbe.isgbetol/xs_start_neu/\&p_aid=3\&p_aid=95629922\&nummer=322\&p_sprache=D\&p_indsp=4050\&p_aid=48733270

[39] Statistisches Landesamt Rheinland-Pfalz. (o. J.). Abgerufen 9. Februar 2020, von

https://www.statistik.rlp.de/de/gesellschaft-staat/bevoelkerung-und-gebiet/basisdaten-regional/

[40] Statistisches Landesamt Rheinland-Pfalz (2018): Landesinformationssystem - Fortschreibung der Bevölkerung. Bad Ems.

[41] Seyit M, Yilmaz A, Seyit DA, Ozen M. Cost Analysis of Emergency

Department Visits by Geriatric Patients Living in Nursing Homes. J Coll Physicians Surg Pak. 2019 Jul;29(7):658-660. doi: $10.29271 /$ jcpsp.2019.07.658.

[42] Brown E, Sindelar J. The emergent problem of ambulance misuse. Ann Emerg Med. 1993 Apr;22(4):646-50. DOI: https://doi.org/10.1016/S0196-0644(05)81841-4

[43] Günther A, Schmid S, Weidlich-Wichmann U, Bleidorn J, Buhr-Riehm B, Schubert R, Schwartze J, Schneider $\mathrm{N}$, Hasseler M. Emergency care in nursing homes in the City of Braunschweig: A cross-

sectoral view with indicators from deaths, resuscitation, emergency department visits and EMS deployment. Z Evid Fortbild Qual Gesundhwes. 2019 May;141-142:1-10. doi: 10.1016/j.zefq.2019.02.010. Epub 2019 Mar 26. DOI: https://doi.org/10.1016/j.zefq.2019.02.010

[44] Björck M, Wijk H. Is hospitalisation necessary? A survey of frail older persons with cognitive impairment transferred from nursing homes to the emergency department. Scand J Caring Sci. 2018 Sep;32(3):1138-1147. doi:

10.1111/scs.12559. Epub 2018 Feb 12. https://doi.org/10.1111/scs.12559

[45] Kuek BJW, Li H, Yap S, Ng MXR, Ng YY, White AE, Ong MEH. Characteristics of Frequent Users of Emergency Medical Services in Singapore. Prehosp Emerg Care. 2019 Mar-Apr;23(2):215-224. doi: 10.1080/10903127.2018.1484969. Epub 2018 Aug 17.

[46] Schmiedhofer M, Möckel M, Slagman A, Frick J, Ruhla S, Searle J. Patient motives behind low-acuity visits to the emergency department in Germany: a qualitative study comparing urban and rural sites. BMJ Open. 2016 Nov 16;6(11):e013323. doi: 10.1136/bmjopen-2016-013323.

[47] Farmer J, Iversen L, Campbell NC, Guest C, Chesson R, Deans G, MacDonald J. Rural/urban differences in accounts of patients' initial decisions to consult primary care. Health Place. 2006 Jun;12(2):210-21.

https://doi.org/10.1016/j.healthplace.2004.11.007

[48] Breuer F, Pommerenke C, Wollenhaupt L et al. Vorkommen von Frequent Usern und Frequent Callern in einem großstädtischen Rettungsdienst: Indikatoren eines unzureichenden Gesundheits- und Sozialsystems?. Notfall Rettungsmed 23, 122-131 (2020). https://doi.org/10.1007/s10049-019-0600-6

[49] Norman C, Mello M, Choi B. Identifying Frequent Users of an Urban Emergency Medical Service Using Descriptive Statistics and Regression Analyses. West J Emerg Med. 2016 Jan;17(1):39-45. doi: 10.5811/westjem.2015.10.28508.

Page $11 / 15$ 
Epub 2016 Jan 12.

[50] Tangherlini N, Pletcher MJ, Covec MA, Brown JF. Frequent use of emergency medical services by the elderly: a casecontrol study using paramedic records. Prehosp Disaster Med. 2010 May-Jun;25(3):258-64.

DOI: https://doi.org/10.1017/S1049023X0000813X

[51] Squire BT, Tamayo A, Tamayo-Sarver JH. At-risk populations and the critically ill rely disproportionately on ambulance transport to emergency departments. Ann Emerg Med. 2010 Oct;56(4):341-7. doi:

10.1016/j.annemergmed.2010.04.014. Epub 2010 Jun 15.

\section{Tables}

Due to technical limitations, table 1 and 2 is only available as a download in the Supplemental Files section.

\section{Figures}

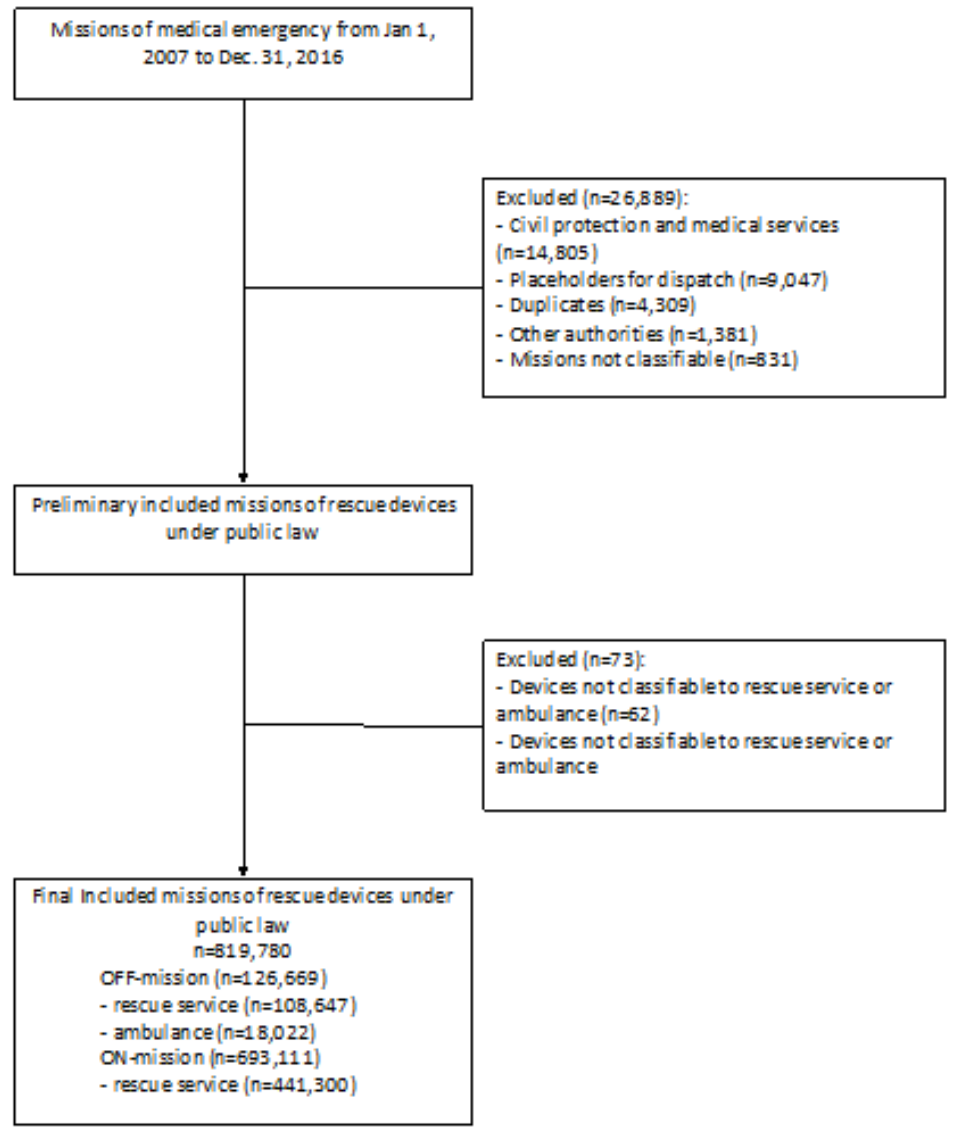

Figure 1

Study Flow Chart. Study Flow Chart with inclusion and exclusion criteria 

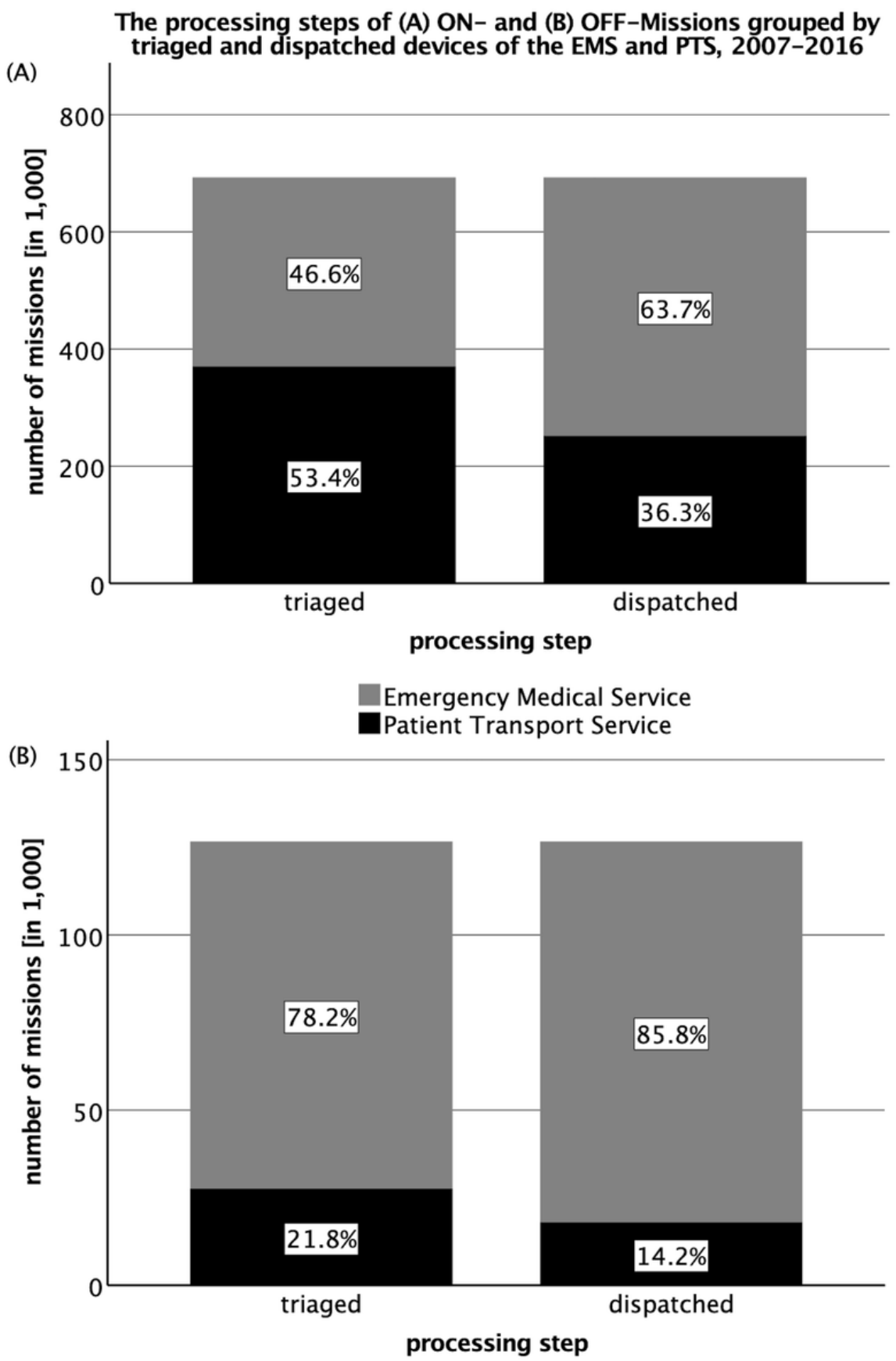

\section{Figure 2}

The processing steps of ON- and OFF-Missions grouped by triaged and dispatched devices of the EMS and PTS. 20072016. A Grouping of all ON-Missions of the EMS and PTS according to the processing steps Triaged and Dispatched, B corresponding grouping of all OFF-Missions. EMS Emergency Medical Service, PTS Patient Transport Service. 


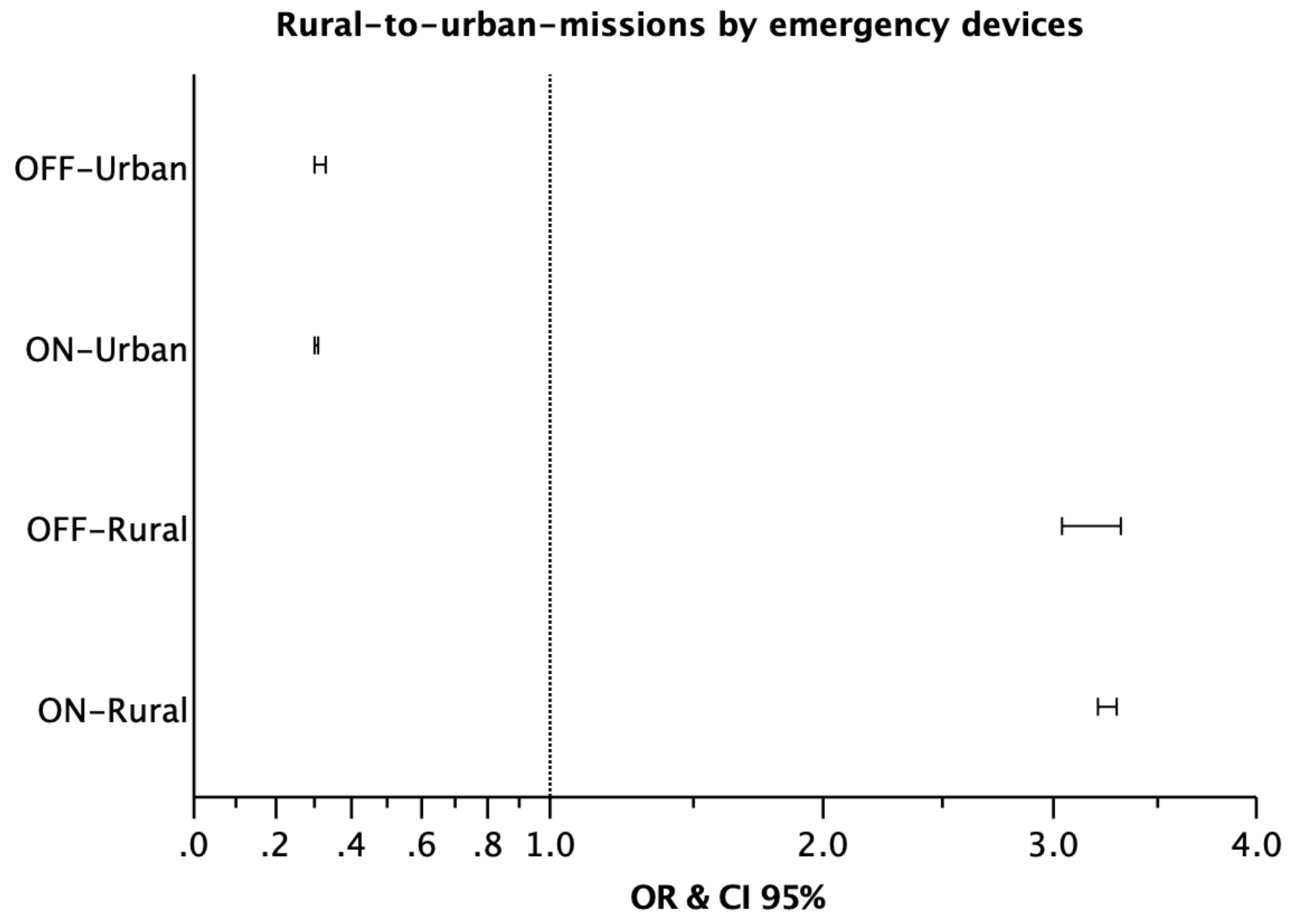

Figure 3

Rural-to-urban-missions by emergency devices. Odds ratios of ON- and OFF-Missions in urban and rural settings by emergency devices, 2007-2016. The odds of emergency devices for ON- and OFF-Missions in rural areas are significantly high. 


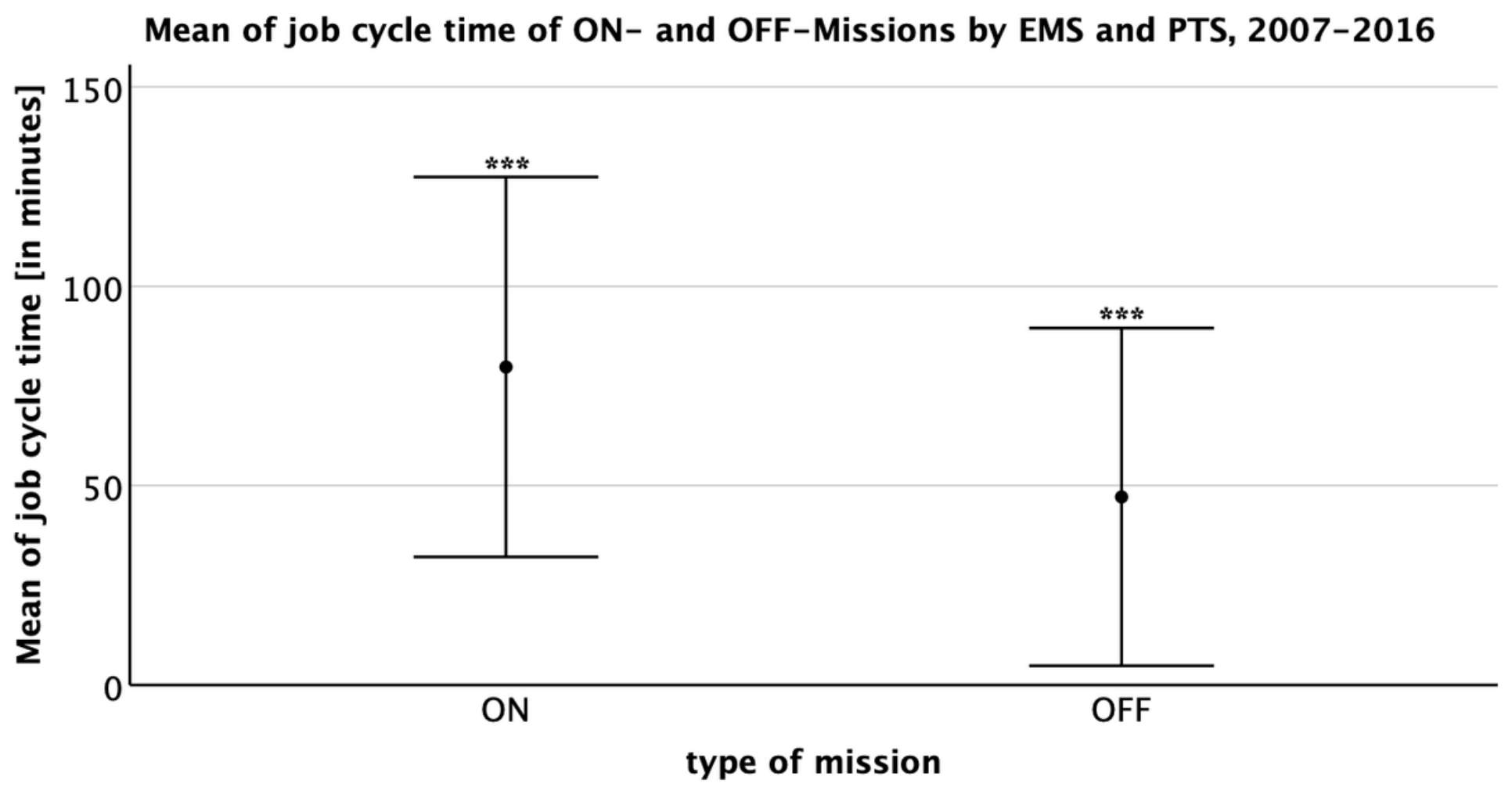

Figure 4

Mean of job cycle time of ON- and OFF-Missions by EMS and PTS, 2007-2016. Means of the job cycle time of ON-and OFF-Missions of the EMS and PTS in minutes from 2007 to 2016 with standard deviation. For the sake of clarity, the upper extreme values have been hidden.

\section{Supplementary Files}

This is a list of supplementary files associated with this preprint. Click to download.

- Table1.pdf

- Table2.pdf 